Acknowledgments. This report is part of an ongoing quality assurance project regarding outbreak management at the German consulting center for infection control.

Financial support. This work was funded with institutional funds only.

Conflict of interest. S.S.S. is shareholder of Deutsches Beratungszentrum für Hygiene (BZH GmbH) and receives royalties from Springer, Thieme, Deutsche Krankenhausverlagsgesellschaft, and Consilum infectiorum.

\section{References}

1. Schulz-Stübner S, Reska M, Hauer T, Schaumann R. First results of the German consulting center for infection control outbreak registry. Dtsch Med Wochenschr 2016;141(6):e47-e52.

2. Neufeind J, Wenchel R, Bödeker B, Wichmann O: OKaPII-Studie zur Influenza-Impfung: Impfquoten und Impfmotivation bei Klinikpersonal in der Influenza-Saison 2016/2017. Epid Bull 2018;32:313-321.

3. Doll MK, Winters N, Boikos C, Kraicer-Melamed H, Gore G, Quach C. Safety and effectiveness of neuraminidase inhibitors for influenza treatment, prophylaxis, and outbreak control: a systematic review of systematic reviews and/or meta-analyses. I Antimicrob Chemother 2017;72:2990-3007.
4. Mitchell KJ, Vayalumkal JV. Sickness presenteeism: The prevalence of coming to work while ill among paediatric resident physicians in Canada. Paediatr Child Health 2017;22:84-88.

5. Tan PC, Robinson G, Jayathissa S, Weatherall M. Coming to work sick: a survey of hospital doctors in New Zealand. N Z Med J 2014;127:23-33.

6. Leistner R, Buchwald D, Beyer M, Philipp S. Scabies outbreak among healthcare workers in a German acute care hospital. I Infect Prev 2017:18:189-219.

7. Buehlmann M, Beltraminelli H, Strub C. Scabies outbreak in an intensive care unit with 1,659 exposed individuals-key factors for controlling the outbreak. Infect Control Hosp Epidemiol 2009;30:354-360.

8. Garcia C, Iglesias D, Terashima A, Canales M, Gotuzzo E. Use of ivermectin to treat an institutional outbreak of scabies in a low-resource setting. Infect Control Hosp Epidemiol 2007;28:1337-1338.

9. Dulon M, Peters C, Schablon A, Nienhaus A. MRSA carriage among healthcare workers in non-outbreak settings in Europe and the United States: a systematic review. BMC Infect Dis 2014;14:363.

10. Empfehlung der Kommission für Krankenhaushygiene und Infektionsprävention (KRINKO) beim Robert Koch-Institut. Empfehlungen zur Prävention und Kontrolle von Methicillin-resistenten Staphylococcus aureus-Stämmen (MRSA) in medizinischen und pflegerischen Einrichtungen. Bundesgesundheitsbl 2014;57:696-732.

\title{
Foodborne illness outbreak due to Staphylococcus aureus among hospital staff following Hurricane Harvey
}

\author{
Lucila Marquez MD, MPH ${ }^{1,2}$, Tjin H. Koy BS, MPH, $\mathrm{CIC}^{2}$, Cheryl R. Baker RN, BSN ${ }^{2}$, Jeanine Graf $\mathrm{MD}^{3}$, \\ Elaine M. Whaley MSN, $\mathrm{CIC}^{2}$ and Judith R. Campbell MD ${ }^{1,2}$ \\ ${ }^{1}$ Baylor College of Medicine, Section of Infectious Diseases, Department of Pediatrics, Houston, Texas, ${ }^{2}$ Texas Children's Hospital, Department of Infection \\ Control and Prevention, Houston, Texas and ${ }^{3}$ Baylor College of Medicine, Section of Critical Care Medicine, Department of Pediatrics, Houston, Texas
}

To the Editor-After Hurricane Harvey, an outbreak of foodborne illness occurred at a hospital in Houston. An investigation implicated a donated catered meal contaminated with Staphylococcus aureus. Prompt investigation and interventions prevented the disruption of patient care.

The Centers for Disease Control and Prevention (CDC) estimates that 48 million people in the United States develop foodborne disease each year. ${ }^{1,2}$ More than 9 million cases are due to food contaminated with 1 of 31 known foodborne illness pathogens. ${ }^{1}$ Gastrointestinal illness after natural disasters result from the disruption of public works or pathogen transmission in crowded temporary housing. ${ }^{3,4}$ We report a foodborne outbreak that occurred at a hospital in Houston, Texas, in 2017 following Hurricane Harvey.

On September 1, 2017, a donated catered meal was served to staff in the hospital cafeteria. The following day, infection control (IC) staff were notified of several cases of gastrointestinal illness among staff who had consumed the meal.

Author for correspondence: Judith R. Campbell MD, Texas Children's Hospital, 1102 Bates Avenue, Suite 1120, Houston, Texas ZIPCODE. Email: judithc@bcm.edu

Cite this article: Marquez L, et al. (2019). Foodborne illness outbreak due to Staphylococcus aureus among hospital staff following Hurricane Harvey. Infection Control \& Hospital Epidemiology 2019, 40, 115-117. doi: 10.1017/ice.2018.272

\section{Investigation}

The meal was delivered to the hospital and was received by the manager of food services. He was interviewed on September 2, 2017, to collect information about the menu and food condition when it was delivered and served. All food was served within 2 hours of arrival.

Staffing $\operatorname{logs}$ were used to identify individuals who were working on September 1,2017. A case was defined as any staff present when the meal was served that developed acute onset of gastrointestinal symptoms (eg, emesis, diarrhea, abdominal pain, cramping, or bloody stool).

A questionnaire that assessed food consumed, environmental exposures, and symptoms was administered to all potentially exposed staff. Leaders notified staff of the possible foodborne outbreak and administered the questionnaire. Data from completed questionnaires were collated for our retrospective cohort study. Attack rates and risk ratios for specific food items were calculated. The Harris County Health Department was notified.

\section{Control Measures}

Staff were instructed not to eat any leftover food. The food was secured, and samples of pork sausage, pulled pork, brisket, and 
Table 1. Food Items Served at Catered Buffet and Relative Risk of Acute Gastrointestinal Illness Among Hospital Staff

\begin{tabular}{|c|c|c|c|}
\hline Exposure & $\begin{array}{l}\text { Illness in Those Who Ate } \\
\text { Specified Food, No./Total No. (\%) }\end{array}$ & $\begin{array}{l}\text { Illness in Those Who Did Not Eat } \\
\text { Specified Food, No./Total No. (\%) }\end{array}$ & $\begin{array}{l}\text { Relative Risk } \\
\qquad(95 \% \mathrm{Cl})\end{array}$ \\
\hline Brisket & $36 / 55(65)$ & $14 / 25(56)$ & $1.17(0.79-1.74)$ \\
\hline Pulled pork & $32 / 45(71)$ & $17 / 35(49)$ & $1.46(0.99-2.16)$ \\
\hline Pork sausage & $21 / 27(78)$ & $28 / 53(53)$ & $1.47(1.06-2.04)$ \\
\hline Chicken & $14 / 25(56)$ & $35 / 55(64)$ & $0.88(0.59-1.31)$ \\
\hline Hot dogs & $5 / 7(71)$ & $44 / 73(60)$ & $1.19(0.72-1.96)$ \\
\hline Chips & $13 / 18(72)$ & $36 / 62(58)$ & $1.24(0.87-1.76)$ \\
\hline Cookies & $1 / 2(50)$ & $48 / 78(62)$ & $0.81(0.20-3.28)$ \\
\hline Yogurt parfait & $10 / 12(83)$ & $39 / 68(57)$ & $1.45(1.05-2.01)$ \\
\hline
\end{tabular}

chicken were submitted to a certified food safety reference laboratory for testing.

Ill hospital staff were excluded from work until resolution of symptoms for 24 hours. Hand hygiene practice was emphasized, and nursing staff were instructed to report any patients with new onset vomiting or diarrhea to infection control staff. Medical records of inpatients were reviewed daily for these symptoms and/ or orders for stool studies.

\section{Results}

All 191 staff who were working at the hospital when the meal was served were contacted, and 92 (48\%) reported eating some of the catered meal. Of these 92 consumers, 50 (54\%) reported acute onset of gastrointestinal symptoms within 14 hours of the meal being served and were defined as cases. All ill hospital staff recovered within 24 hours. Those who were well when they were initially contacted remained symptom free. No hospitalized patients developed new gastrointestinal symptoms.

Of the 50 cases, 49 (98\%) fully completed the questionnaire, compared to 31 of $42(74 \%)$ asymptomatic hospital staff. The relative risk of illness from eating pork sausage and yogurt was 1.47 (95\% confidence interval [CI], 1.06-2.04) and 1.45 (95\% CI, 1.05-2.01), respectively (Table 1). Exposure to flood water or flooded homes was not associated with acute gastrointestinal symptoms, and no staff were staying in shelters.

Food items were tested for foodborne pathogens with a short incubation period: S. aureus, shigatoxin-producing E. coli, and Bacillus cereus. Staphylococcus aureus were isolated from portions of pulled pork and pork sausage. Testing for S. aureus enterotoxins was not available. Brisket and chicken were negative for these pathogens. No yogurt was available for testing. Stool samples from ill staff were not available for testing.

\section{Discussion}

Staphylococcus aureus is 1 of 31 known causes of foodborne illness and outbreaks. Foods implicated in S. aureus foodborne illness include meats, salads, pastries, and dairy products. ${ }^{1,2,5-8}$ In the United States from 1998 to 2008, 458 foodborne disease outbreaks that occurred due to $S$. aureus were reported to the
$\mathrm{CDC}^{2}$ The source of $S$. aureus contamination is usually colonized or infected food handlers, and if the strain of $S$. aureus produces 1 of several heat-stable enterotoxins, illness may occur even if food is kept at the recommended temperature..$^{5-7}$ This outbreak was associated with a catered meal served to hospital staff following a natural disaster. Foodborne outbreaks reported in hospitals have been linked to ill food handlers and/or contaminated foods prepared in the hospital food service department and have impacted both hospital staff and patients. ${ }^{9}$ Fortunately, no patients were affected by this outbreak.

In the setting of natural disasters, most foodborne illness is associated with water contamination or transmission of highly contagious agents in crowded living conditions. ${ }^{4,10}$ Emergency preparedness for institutions such as hospitals involves securing stockpiles of water and nonperishable food. However, after such disasters, volunteers often donate supplies, water, and catered meals, especially for first responders and hospitals. Institutions should be cautious when accepting donations of catered meals and should consider whether safe food handling practices have been followed because foodborne outbreaks can impact the delivery of needed services after natural disasters. Although the outbreak was reported to the health department, the catering business was not immediately investigated given the tremendous disruption of many public health services for weeks following the hurricane.

Limitations include bias introduced by the higher response rate in symptomatic staff. Additionally, we were unable to test yogurt, which had a significantly elevated risk for illness. Testing for Staphylococcus enterotoxins and of stool from case patients was not available.

Acknowledgments. The authors thank the staff, physicians and administration for their assistance in this investigation.

Financial support. No financial support was provided relevant to this article.

Conflicts of interest. All authors report no conflicts of interest relevant to this article.

\section{References}

1. Scallan E, Hoekstra RM, Angulo FJ, et al. Foodborne illness acquired in the United States-major pathogens. Emerging Infect Dis 2011;17:7. 
2. Bennett DS, Walsh KA, Gould H. Foodborne disease outbreaks caused by Bacillus cereus, Clostridium perfringens, and Staphylococcus aureusUnited States, 1998-2008. Clinical Infect Dis 2013;57:425.

3. Watkins RR. Gastrointestinal infections in the setting of natural disasters. Curr Infect Dis Rep 2012;14:47-52.

4. Yee EL, Palacio H, Atmar RL, et al. Widespread outbreak of norovirus gastroenteritis among evacuees of Hurricane Katrina residing in a large "megashelter" in Houston, Texas: lessons learned for prevention. Clin Infect Dis 2007;44:1032-1039.

5. Kadariya J, Smith TC, Thapaliya D. Staphylococcus aureus and staphylococcal food-borne disease: an ongoing challenge in public health. BioMed Res Int 2014; article ID 827965:1-9.

6. Pillsbury A, Chiew M, Bates J, Sheppeard V. An outbreak of staphylococcal food poisoning in a commercially catered buffet. Commun Dis Intel Q Rep 2013;37:E144-E148.
7. Hennekinne JA, De Buyser M-L, Dragacci S. Staphylococcus aureus and its food poisoning toxins: characterization and outbreak investigation. FEMS Microbiol Rev 2012;36:815-836.

8. Ercoli L, Gallina S, Nia Y, et al. Investigation of a staphylococcal food poisoning outbreak from a chantilly cream dessert, in Umbria (Italy). Foodborne Path Dis 2017;14:407-413.

9. Elward A, Grim A, Schroeder P, et al. Outbreak of Salmonella javiana infection at a children's hospital. Infect Contol Hosp Epidemiol 2006;27:586-592.

10. Bloom MS, Palumbo J, Saiyed N, Lauper U, Lin S. Food and waterborne disease in the greater New York City area following Hurricane Sandy in 2012. Disaster Med Public Health Prepare 2016;10:503-511.

\title{
Laterality of a short-term peripheral intravenous catheter does not affect complications or patient satisfaction: a subanalysis of the One Million Global Peripheral Intravenous Catheter Study
}

\author{
Rami Sommerstein MD, Lisa Kottanattu MD and Jonas Marschall MD, MSc \\ Department of Infectious Diseases, Bern University Hospital, Bern, Switzerland
}

To the Editor-The One Million Global Peripheral Intravenous Catheter Study (OMG PIVC) was the largest prevalence study to date on the use and management of short-term peripheral intravenous catheters (PIVC) in adult and pediatric inpatients from 49 countries. ${ }^{1}$ The authors found that many PIVCs were placed in areas of flexion, were symptomatic or idle, had suboptimal dressings, or lacked adequate documentation, which suggested an inconsistency between recommendations in PIVC management and current practice. ${ }^{1}$

Although few data are available on the effect of laterality on (peripherally inserted) central venous catheters, ${ }^{2-4}$ information is completely lacking for PIVCs. Thus, we supplemented the data from the 302 PIVCs our center contributed to the OMG PIVC study with additional variables on PIVC laterality and patient handedness. All other variables were collected as described in detail in the OMG PIVC study. ${ }^{1}$

Our aim was to correlate the laterality of PIVCs placed in the upper extremity with the outcome rates of complications and patient satisfaction. We included 291 of 302 PIVCs (96.4\%) that were inserted at the upper extremity and where information on laterality was available. Characteristics such as handedness, bed days at the time of data collection (April 15, 2015) and PIVC insertion position at the upper extremity (wrist and/or hand versus forearm and/or elbow) did not differ significantly depending on the laterality of the PIVC (Table 1). Also, PIVC outcomes and patient satisfaction did not depend on PIVC laterality (Table 1). Based on this, we conclude that laterality should not influence the decision regarding where to insert a PIVC at the upper extremity.

Acknowledgments. We acknowledge the One Million Global Peripheral Intravenous Catheter (OMG PIVC) study team for the original concept and study design (Evan Alexandrou, Gillian Ray-Barruel, Niall Higgins, Steven Frost, Peter Carr, Sheila Inwood, Frances Lin, Leonard Mermel and Claire Rickard). Also, we thank the infection prevention team at Bern University Hospital for data collection.

Financial support. No financial support was provided relevant to this article.

Conflicts of interest. All authors report no conflicts of interest relevant to this article.

\section{References}

1. Alexandrou E, Ray-Barruel G, Carr PJ, Frost SA, et al. Use of short peripheral intravenous catheters: characteristics, management, and outcomes worldwide. J Hosp Med 2018. doi: 10.12788/jhm.3039.

2. Engstrom BI, Horvath JJ, Stewart JK, et al. Tunneled internal jugular hemodialysis catheters: impact of laterality and tip position on catheter dysfunction and infection rates. J Vasc Interv Radiol 2013;24:1295-1302.

3. Sperry BW, Roskos M, Oskoui R. The effect of laterality on venous thromboembolism formation after peripherally inserted central catheter placement. J Vasc Access 2012;13:91-95.

4. Paquet F, Boucher LM, Valenti D, Lindsay R. Impact of arm selection on the incidence of PICC complications: results of a randomized controlled trial. J Vasc Access 2017;18:408-414. 